philanthropic arm, has turned its findings into Google Flu Trends, a free daily flu forecast for the United States. It plans to roll out the service to other countries, languages and diseases.

"Google Flu Trends nicely illustrates both the broad coverage and fine-grained detail that one can get from search-engine query-log data," says Jon Kleinberg, a specialist in network analysis at Cornell University in Ithaca, New York.

Scientists have only begun to scratch the surface of the potential of large web data sets - often because companies are reluctant to share their data because of both real and perceived privacy concerns, says David Lazer of the John F. Kennedy School of Government at Harvard University. "It is difficult to get access to such data, and so it should be, because there are confidentiality issues," he says. In the flu-prediction case, this was much less of an issue, says Lazer, as

\section{TRACKING THE FLU}

The relative frequency of flu-related keywords in Google searches closely tracks flu statistics in the US mid-Atlantic region as monitored by government officials.

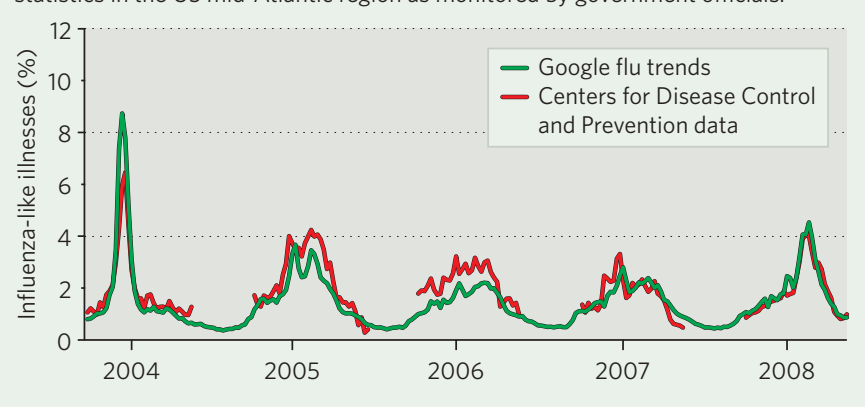

anticipated, around a week in advance, the official Canadian FluWatch reports ${ }^{3}$ - for a total monitoring cost per season of about Can\$364 (US\$295).

The Google and Yahoo work shows that real-time electronic data can improve on government data, says Marshall Van Alstyne, an expert on information economics at Boston University in Massachusetts. "No doubt, it presages a trend toward leading rather than lagging indicators for other socially important the data used were large pooled aggregates of search-term frequencies, from which it would be impossible to obtain information on individuals' searches.

In 2006, lacking access to Google databases, Gunther Eysenbach of the University of Toronto took out a Google Ad that pointed users searching for flurelated terms to a flu educational website. The patterns of clicks on the ad correctly phenomena," he says. That might even include the credit crisis, he says - because banks' own activities give them better and earlier data on macroeconomic trends than those that government agencies can collect. Declan Butler

1. Polgreen, P. M., Chen, Y., Pennock, D. M. \& Nelson, F. D. Clin. Infect. Dis. 47, 1443-1448 (2008).

2. Ginsberg, J. et al. Nature doi:10.1038/nature07634 (2008). 3. Eysenbach, G. AMIA Annu. Symp. Proc. 244-248 (2006).

\title{
Gene testing of embryos needs guiding
}

Couples might soon use the technologies sold by personalgenomics companies to choose the genetic make-up of their children.

Last week, at a meeting of the American Society for Reproductive Medicine in San Francisco, California, researchers cautioned that they do not yet advocate this use of genetic tests. But as the technology advances, consumer demand is likely to overwhelm societal ethical qualms. "If people think they can make their babies healthier at year one, year two, or in utero, they will do it," says Jacques Cohen, research director at Reprogenetics, a genetic-testing company in West Orange,

New Jersey.

Fertility doctors already use genetic analyses to check cells from embryos for specific large genetic abnormalities, such as the loss or gain of entire chromosomes. These analyses help parents choose which embryos to transfer into a woman's uterus during in vitro fertilization procedures. But now scientists have begun more detailed genetic analyses that rely on microarrays to survey an embryo's genome.

Some of the microarrays contain thousands of tiny genetic markers called single nucleotide polymorphisms, or SNPs, that are used to reconstruct the embryo's chromosomal make-up.

The 'SNP chips' used in these tests, which are sold in the United States and could soon be available in the United Kingdom, are similar to those used by personalgenomics companies. That means they could potentially be used to estimate an embryo's risk of adultonset diseases - such as diabetes and obesity - and other traits, such as hair, eye and skin colour.

Professional societies and governments have not yet decided how to handle preimplantation testing for the risks of such diseases, because it has never before been possible. The UK Human Fertilisation and Embryology Authority, for example, has allowed clinics to use preimplantation genetic diagnosis to screen for serious adult-onset diseases caused by single genes, such as cancer syndromes, and for genes that are likely but not certain to cause disease, such as the breast cancer risk gene $B R C A 1$.

But most common adult-onset diseases, such as diabetes, have multiple genetic contributors most of which are still unknown. And SNPs only give a very rough estimate of a person's risk of a disease; they do not determine that an embryo will grow into a person who will actually get that disease.

Reproductive geneticists seem wary of treading on such controversial ground. "We have this information," says William Kearns, director of the Shady Grove Center for Preimplantation Genetics in Rockville, Maryland. "But just because we have it doesn't mean we should use it." Kearns's centre will begin offering SNPbased analyses of chromosomal abnormalities next month, but will not report risk information about multi-gene complex diseases to prospective parents.

Neither will Gene Security
Network, a company in Redwood City, California, that has already begun selling microarraybased preimplantation genetic diagnosis tests of chromosomal abnormalities and some diseases to fertility clinics. "Any disease we screen for is nasty, early-onset and ethically uncomplicated," says Dave Johnson, Gene Security Network's director of research and development.

Alan Handyside, the inventor of preimplantation genetic diagnosis and director of the London Bridge Fertility, Gynaecology and Genetics Centre, UK, is also developing a microarray-based test, which he hopes will enter a clinical trial in the next several months.

Cohen says that as the understanding of disease genetics progresses, use of tests that seem controversial now may become more acceptable in the future: "If you had the chance to decrease your child's risk of a disease like diabetes and you didn't, society would blame you." Erika Check Hayden 